\title{
New promising Co-free thermoelectric ceramic based on Ba-Fe-oxide
}

G. Constantinescu ${ }^{1,}{ }^{*}$, J. C. Diez ${ }^{1}$, Sh. Rasekh ${ }^{1}$, M. A. Madre ${ }^{1}$, M. A. Torres ${ }^{2}$, A. Sotelo ${ }^{1}$

${ }^{1}$ Instituto de Ciencia de Materiales de Aragón (CSIC-Universidad de Zaragoza), $M^{a}$ de Luna, 3. 50018 Zaragoza, Spain.

2 Departamento de Ingeniería de Diseño y Fabricación, Universidad de Zaragoza, Ma de Luna, 3. 50018 Zaragoza, Spain.

\begin{abstract}
Thermoelectric ceramics are based in a limited number of transition metal oxides ( $\mathrm{Co}, \mathrm{Mn}, \mathrm{Ni}, \ldots)$ which produce materials with high thermoelectric performances. Based on previously existing thermoelectric phases, the phase diagram equilibrium can help to design new thermoelectric ceramics based on other transition metals (for example, $\mathrm{Fe}$ ). In this work, $\mathrm{BaFeO}_{\mathrm{x}}$ ceramics have been prepared by the classical solid state method using different sintering temperatures. The produced materials have shown promising thermoelectric properties when treatment temperatures are in the perovskite zone domain of the phase equilibrium diagram. In spite of the good values for the Seebeck coefficients, power factor is low due to the high resistivities measured in all cases.
\end{abstract}

Keywords: Synthesis; Electrical properties; Thermopower; Iron oxide.

*Corresponding author: gconstan@unizar.es

Tel.: +34 976762617; Fax: +34 976761957 


\section{Introducción}

Nowadays, thermoelectric (TE) power generation technology is regarded as one of the most promising methods to harvest energy from wasted heat and natural sources. Thermoelectric energy conversion has been shown as an effective technology that can be used to transform thermal to electrical energy. From this point of view, it can help to solve global warming by reducing $\mathrm{CO}_{2}$ emissions due to the efficiency improvement in energy transformation systems. The conversion efficiency of TE materials is quantified by the dimensionless figure of merit $\mathrm{ZT}$, defined as

$$
\mathrm{ZT}=\mathrm{TS}^{2} / \rho \kappa \text { (in which } \mathrm{S}^{2} / \rho \text { is also called power factor, } \mathrm{PF} \text { ) }
$$

where $S$ is the Seebeck coefficient (or thermopower), $\rho$ the electrical resistivity, $\kappa$ the thermal conductivity, and $T$ is the absolute temperature [1]. From this expression, it is obvious that a performant TE material must posses a high thermopower, together with low electrical resistivity and thermal conductivity. So far, semiconducting and intermetallic materials have been used to manufacture TE modules, mainly to be applied as cooling devices. On the other hand, they are usually composed of heavy and/or dangerous elements which can melt, evaporate or oxidize at high temperatures under air. As a consequence, they cannot be employed for waste heat recovery in applications requiring high temperatures. The solution of all these problems started with the discovery of large thermoelectrical properties in a layered ceramic material, $\mathrm{Na}_{x} \mathrm{CoO}_{2}$ [2], which was found to posses a high $\mathrm{Z}$ value $\left(8.8 \times 10^{-4} \mathrm{~K}^{-1}\right)$ and large thermopower $\left(\sim 100 \mu \mathrm{V} \mathrm{K}^{-1}\right)$ at $300 \mathrm{~K}$. This kind of materials is composed of less dangerous and cheaper elements than the classical semiconducting and intermetallic ones. Moreover, they can operate at high temperatures, under air, for long time without degradation. As a consequence, this material has opened a new research field in which great efforts have been devoted to explore new $\mathrm{CoO}$ families with high thermoelectric performances. Some other layered cobaltites, such as $\left[\mathrm{Ca}_{2} \mathrm{CoO}_{3}\right]\left[\mathrm{CoO}_{2}\right]_{1.62}$ and $\left[\mathrm{Bi}_{0.87} \mathrm{SrO}_{2}\right]_{2}\left[\mathrm{CoO}_{2}\right]_{1.82}$ were also found to exhibit attractive thermoelectric properties [3-6]. In any case, their performances must be increased before they can be used in practical applications requiring high efficiency. One of the explored ways to raise their thermoelectric properties has been by doping with metallic oxides, for example 
$\mathrm{Gd}^{+3}$ and $\mathrm{Y}^{+3}$ for $\mathrm{Ca}^{+2}$ in Ca-Co-O [7], $\mathrm{Pb}^{+2}$ for $\mathrm{Bi}^{+3}$ in Bi-AE-Co-O (AE: alcaline earth) [8-10], or $\mathrm{Fe}, \mathrm{Mn}$ and $\mathrm{Cu}$ for $\mathrm{Co}$ in $\mathrm{Ca}-\mathrm{Co}-\mathrm{O}$ [11], or by Ag metallic additions [12]. Other explored possibilities have been based on the grain orientation by different techniques as spark plasma sintering (SPS) [13,14], sinter-forging [15], template grain growth (TGG) [16], laser floating zone (LFZ) melting technique [17], or the new electrically assisted laser floating zone method (EALFZ) [18]. Most of the research works published in the last years are devoted to the improvement of the performances of relatively well-known ceramics and, consequently, not many totally new thermoelectric materials have been recently reported.

Taking into account that many thermoelectric oxides show the perovskite structure $[19,20]$, it has been decided to test the thermoelectric properties of the perovskite phase in the $\mathrm{Ba}-\mathrm{Fe}-\mathrm{O}$ system $\left(\mathrm{BaFeO}_{3-\mathrm{x}}\right)$, which is similar to the already reported $\mathrm{Ca}-\mathrm{Fe}-\mathrm{O}$ perovskite [21]. The objective of this study is developing a new thermoelectric oxide ceramic based on cheaper and more abundant cations than those used in the usually reported thermoelectric materials. The phase equilibrium diagram has been used to design and produce a stable compound at high-temperature which could be used in thermoelectric applications. It is also studied the effect of sintering temperature on the microstructure and thermoelectric properties of $\mathrm{BaFeO}_{3-\mathrm{x}}$.

\section{Experimental}

From the $\mathrm{BaO}-\mathrm{Fe}_{2} \mathrm{O}_{3}$ phase diagram equilibria [22] it has been found that many phases can be obtained by the combination of $\mathrm{BaO}$ and $\mathrm{Fe}_{2} \mathrm{O}_{3}$. On the other hand, pure perovskite phase can be obtained for $\mathrm{Fe}_{2} \mathrm{O}_{3}$ proportions higher than $31.5 \mathrm{~mol} \%$ at minimum temperatures which are increasing, from $943^{\circ} \mathrm{C}$ to around $960{ }^{\circ} \mathrm{C}$, when $\mathrm{Fe}_{2} \mathrm{O}_{3}$ proportion is increased. As a consequence, the initial stoichiometry has been fixed in $33.33 \mathrm{~mol} \% \mathrm{Fe}_{2} \mathrm{O}_{3}$ and $66.66 \mathrm{~mol} \% \mathrm{BaO}$ to get a 1:1 for the Ba:Fe cation relationship.

The $\mathrm{BaFeO}_{\mathrm{x}}$ powders used in this work were prepared from commercial metallic oxides and carbonates by the classical solid state route. $\mathrm{Fe}_{2} \mathrm{O}_{3}$ (98\%, Panreac) and $\mathrm{BaCO}_{3}(98.5 \%$, Panreac) were ball-milled for 30 minutes at $300 \mathrm{rpm}$ in acetone media. The resulting mixture was dried using infrared heating lamps and subsequently placed in a furnace where it was slowly heated to $750{ }^{\circ} \mathrm{C}$, for 
$12 \mathrm{~h}$, followed by slow cooling. The powder was then mechanically ground and heated again at $800{ }^{\circ} \mathrm{C}$ for $12 \mathrm{~h}$, milled and uniaxially pressed at $350 \mathrm{MPa}$ in form of square parallelepipeds ( $\sim 3 \mathrm{~mm} \times 3 \mathrm{~mm} \times 14 \mathrm{~mm}$ ). Finally, the compacts were sintered for $24 \mathrm{~h}$ at 950,1100 and $1200^{\circ} \mathrm{C}$, with a final furnace cooling. Phase identification has been performed using powder X-ray diffraction (XRD) utilizing a Rigaku D/max-B X-ray powder diffractometer (CuK $\alpha$ radiation) with $2 \theta$ ranging between 10 and 60 degrees. Microstructural observations were made on fractured and polished samples in a JEOL 6000 SEM microscope provided with an Energy Dispersive Spectroscopy (EDS) system, used to determine the elemental composition of each phase.

Electrical resistivity and thermopower were simultaneously determined for samples obtained in the different sintering conditions, in steady state mode, by the standard dc four-probe technique in a LSR-3 apparatus (Linseis $\mathrm{GmbH}$ ) between 50 and $800^{\circ} \mathrm{C}$ under He atmosphere. From the electrical resistivity and thermopower values, power factor has been calculated to determine the thermoelectric performances.

\section{Results and discussion}

Powder XRD plots for samples obtained for the different sintering temperatures are represented in Fig. 1. They show similar patterns where the most intense peaks correspond to the crystallographic planes of the $\mathrm{BaFeO}_{2.89}$ [23] indexed in the plot for a $\mathrm{P}_{3} / \mathrm{mmc}$ (\#194) space group. Other peaks (marked with a * and also indexed in this figure) are associated with the $\mathrm{BaO}$ phase [24] and $\mathrm{FeO}$ (marked with $\mathrm{a}+$ ) [25] both with the same Fm-3m (\#225) space group. These results indicate the $\mathrm{BaFeO}_{x}$ perovskite formation together with some secondary phases.

SEM micrographs of representative longitudinal polished sections for the samples sintered at different temperatures are displayed in Fig. 2. In these images, it is clear that samples sintered at $950^{\circ} \mathrm{C}$ show very high porosity (black contrast) together with the coexistence of very big and small particles with different contrasts. When higher sintering temperature is used (see Figs. $2 \mathrm{~b}$ and $\mathrm{c}$ ) a reduction on porosity as well as the homogeneization of the grain sizes can be observed. On the other hand, three main phases (associated to 
different contrasts) can be found in these samples but they can not be easily seen in these micrographs due to the high porosity. In order to indicate the different phases, they have been numbered in a higher magnification micrograph from samples sintered at $1100^{\circ} \mathrm{C}$, which can be seen in Fig. 3. These different phases have been associated to different contrasts, by EDS analysis, in this micrograph. Light grey contrast (\#1) corresponds to the $\mathrm{BaFeO}_{\mathrm{x}}$ phase which is the major one in all cases. Secondary phases are found in lower proportions when sintering temperature is increased (micrographs not shown) and they can be seen as dark grey contrast (\#2), identified as $\mathrm{FeO}$, and grey one (\#3) which shows a Ba-poor composition, approximately $\mathrm{BaFe}_{2} \mathrm{O}_{\mathrm{y}}$ which seems to be a by-product of the $\mathrm{FeO}+\mathrm{BaO}$ reaction to produce $\mathrm{BaFeO}_{\mathrm{x}}$. In any case, no $\mathrm{BaO}$ has been found in all the studied samples. On the other hand, when sintering temperature is increased from 1100 to $1200^{\circ} \mathrm{C}$, it is found a reduction of size and proportions of the darker contrasts ( $\mathrm{FeO}$ and $\mathrm{BaFe}_{2} \mathrm{O}_{\mathrm{y}}$ ) which indicates a higher reaction kinetics induced by the higher sintering temperature.

The temperature $(T)$ dependence of the electrical resistivity $(\rho)$, as a function of the sintering temperature, is shown in Fig. 4. As it can be easily seen, all the samples have been measured in only a small temperature range, $200-500{ }^{\circ} \mathrm{C}$ for the high temperature sintered samples $\left(1100\right.$ and $1200{ }^{\circ} \mathrm{C}$ ) and $650-800{ }^{\circ} \mathrm{C}$ for the ones sintered at $950{ }^{\circ} \mathrm{C}$. It is due to their high resistivity found in the samples in the rest of the measuring range (between 50 and $800^{\circ} \mathrm{C}$ ), which is out-of-range for the measuring system. In these small temperature ranges, all the samples show similar behaviour, semiconducting-like $(\mathrm{d} \rho / \mathrm{dT}<0)$ between 200 to $400^{\circ} \mathrm{C}$ for the high temperature sintered specimens and 650 to $750^{\circ} \mathrm{C}$ for the $950^{\circ} \mathrm{C}$ sintered samples. At higher temperatures they have a metalliclike $(\mathrm{d} \rho / \mathrm{dT}>0)$ behaviour with a very important increase for samples sintered at 1100 and $1200^{\circ} \mathrm{C}$. In any case, the measured values are much higher than the obtained in the usual thermoelectric materials based on cobalt oxide, but it is, in our knowledge, the first time $\mathrm{BaFeO}_{\mathrm{x}}$ has been reported in the literature as thermoelectric ceramic. Evidently, more research work must be performed in this system in order to decrease these high resistivity values, as for example by doping or using different preparation methods, which have been already 
reported to improve thermoelectric properties in other thermoelectric ceramic systems $[8,26,27]$.

Fig. 5 displays the variation of the thermopower as a function of temperature for all the sintering temperatures. All samples exhibit positive values in the whole studied temperature range, confirming a dominating hole conduction mechanism. In this case, two different tendencies can be observed, for samples sintered at 1100 and $1200^{\circ} \mathrm{C}$, the evolution is the same observed for these samples in the resistivity measurements (decrease from 200 to $400{ }^{\circ} \mathrm{C}$ and then increase) while for samples sintered at $950^{\circ} \mathrm{C}$ a linear raise of thermopower with temperature, in the whole measured range, is found. On the other hand, thermopower values are around the typical reported values obtained in other extensively studied p-type thermoelectric ceramics, as the Bi-based misfit cobaltites [28,29]. On the other hand, these values can be considered as relatively low, when taking into account the measured resistivity. As a consequence, they should also be improved by some of the previously proposed ways for decreasing the resistivity values as, for example, the synthetic method modification [30,31].

Finally, power factor has been calculated using electrical resistivity and thermopower values, and represented in Fig. 6 vs. temperature, as a function of sintering temperature. As it can be clearly seen in this graph, samples sintered at high temperatures show very similar values, while those processed at $950{ }^{\circ} \mathrm{C}$ posses very low power factor. Furthermore, in all cases the calculated power factor values are, at present, too low to be considered for practical applications. As a consequence, more research must be performed on the material modification and/or doping, and/or texturing processes to mainly reduce the electrical resistivity values. This reduction would lead to improved materials which could then be used in practical applications with lower materials costs than those used at present.

\section{Conclusions}

The $\mathrm{BaFeO}_{\mathrm{x}}$ perovskite phase has been successfully prepared by a classical solid state method and it has been reported, by the first time in our knowledge, to possess promising thermoelectric properties. Several sintering temperatures, 
i.e. 950,1100 , and $1200^{\circ} \mathrm{C}$, have been used to study the effect of temperature on phase composition and thermoelectric performances. It has been found that low sintering temperature $\left(950^{\circ} \mathrm{C}\right)$ leads to samples with very low microstructural and thermoelectric quality while higher ones $\left(1100\right.$ and $\left.1200^{\circ} \mathrm{C}\right)$ improve the materials properties significantly. On the other hand, more work has to be performed on this material in order to reduce the high electrical resistivity values and, as a consequence, raise power factor. These improvements should make this material attractive for practical applications due to its raw materials lower costs and higher availability, compared with the Cobased materials.

\section{Acknowledgements}

The authors wish to thank the Gobierno de Aragón (Consolidated Research Groups T87 and T12) for financial support and to C. Gallego and C. Estepa for their technical assistance. 


\section{References}

1. I. Terasaki, Y. Sasago, K. Uchinokura. Phys. Rev. B 56, 20, 12685-12687 (1997)

2. R. Funahashi, I. Matsubara, H. Ikuta, T. Takeuchi, U. Mizutani, S. Sodeoka. Jpn. J. Appl. Phys. 39, 11B, L1127-L1129 (2000)

3. A. C. Masset, C. Michel, A. Maignan, M. Hervieu, O. Toulemonde, F. Studer,

B. Raveau, J. Hejtmanek. Phys. Rev. B 62, 1, 166 (2000)

4. H. Leligny, D. Grebille, O. Perez, A. C. Masset, M. Hervieu, B. Raveau. Acta Cryst. B 56, 173-182 (2000)

5. A. Maignan, D. Pelloquin, S. Hebert, Y. Klein, M. Hervieu. Bol. Soc. Esp. Ceram. V. 45, 3, 122-125 (2006)

6. A. Maignan, S. Hebert, M. Hervieu, C. Michel, D. Pelloquin, D. Khomskii. J. Phys.: Condens. Matter. 15, 2711 (2003)

7. H. Q. Liu, X. B. Zhao, T. J. Zhu, Y. Song, F. P. Wang. Current Appl. Phys. 9 , 2, 409-413 (2009).

8. Sh. Rasekh, M. A. Madre, J. C. Diez, E. Guilmeau, S. Marinel, A. Sotelo. Bol. Soc. Esp. Ceram. V. 49, 5, 371-376 (2010).

9. A. Sotelo, E. Guilmeau, Sh. Rasekh, M. A. Madre, S. Marinel, J. C. Diez. J. Eur. Ceram. Soc. 30, 1815-1820 (2010).

10. A. Sotelo, Sh. Rasekh, E. Guilmeau, M. A. Madre, M. A. Torres, S. Marinel, J. C. Diez. Mater. Res. Bull. 46, 2537-2542 (2011).

11. Y. Wang, Y. Sui, P. Ren, L. Wang, X. J. Wang, W. H. Su, H. J. Fan. Chem. Mater. 22, 3, 1155-1163 (2010).

12. A. Sotelo, M. A. Torres, G. Constantinescu, Sh. Rasekh, J. C. Diez, M. A. Madre. J. Eur. Ceram. Soc. 32, 3745-3751 (2012)

13. Zhang Y, Zhang J, Lu Q. Ceram Int 2007;33:1305-8.

14. Noudem J. G., Kenfaui D., Chateigner D., Gomina M. J Electronic Mater 2011;40:1100-6.

15. Prevel M, Perez O, Noudem JG. Solid State Sci 2007;9:231-5.

16. Itahara H, Xia C, Sugiyama J, Tani T. J Mater Chem 2004;14:61-6.

17. A. Sotelo, E. Guilmeau, M. A. Madre, S. Marinel, J. C. Diez, M. Prevel. J. Eur. Ceram. Soc. 27, 3697-3700 (2007) 
18. N. M. Ferreira, Sh. Rasekh, F. M. Costa, M. A. Madre, A. Sotelo, J. C. Diez, M. A. Torres. Mater. Lett. 83, 144-147 (2012)

19. Y. Wang, Y. Sui, X. J. Wang, W. H. Su, W. W. Cao, X. Y. Liu. ACS Appl. Mater. Interfaces 2, 8, 2213-2217 (2010).

20. F. P. Zhang, X. Zhang, Q. M. Lu, J. X. Zhang, Y. Q. Liu, R. F. Fan, G. Z. Zhang. Phys. B- Condens. Matter 406, 6-7, 1258-1262 (2011).

21. E. Asenath-Smith, I. N. Lokuhewa, S. T. Misture, D. D. Edwards. J. Solid State Chem. 183, 7, 1670-1677 (2010).

22. T. Negas, R. S. Roth. J. Res. Natl. Bur. Stand., Sect. A 73, 4, 425-430 (1969).

23. I. Gil de Muro, M. Insausti, L. Lezama, T. Rojo. J. Solid State Chem. 178, 5, 1712-1719 (2005).

24. D. Taylor. Trans. J. British Ceram. Soc. 83, 5-9 (1984).

25. R. W. G. Wyckoff, E. D. Crittenden. Zeitschrift fuer Kristallographie, Kristallgeometrie, Kristallphysik, Kristallchemie 63, 144-147 (1926).

26. Sh. Rasekh, M. A. Madre, A. Sotelo, E. Guilmeau, S. Marinel, J. C. Diez. Bol. Soc. Esp. Ceram. V. 49, 89-94 (2010)

27. A. Sotelo, E. Guilmeau, M. A. Madre, S. Marinel, S. Lemmonier, J. C. Diez. Bol. Soc. Esp. Ceram. V. 47, 225-228 (2008)

28. J. C. Diez, E. Guilmeau, M. A. Madre, S. Marinel, S. Lemmonier, A. Sotelo. Solid State Ionics 180, 827-830 (2009)

29. J. C. Diez, Sh. Rasekh, M. A. Madre, E. Guilmeau, S. Marinel, A. Sotelo. J. Electron. Mater. 39, 1601-1605 (2010)

30. M. A. Madre, Sh. Rasekh, J. C. Diez, A. Sotelo. Matter. Lett. 64, 2566-2568 (2010).

31. A. Sotelo, Sh. Rasekh, M. A. Madre, E. Guilmeau, S. Marinel, J. C. Diez,. J. Eur. Ceram. Soc. 31, 1763-1769 (2011). 


\section{Figure captions}

Figure 1. $\mathrm{XRD}$ plots obtained on powdered $\mathrm{BaFeO}_{\mathrm{x}}$ specimens sintered at different temperatures. a) 950 , b) 1100 , and c) $1200^{\circ} \mathrm{C}$. Crystallographic planes are indicated for the $\mathrm{BaFeO}_{x}$ perovskite phase. Secondary phases are $\mathrm{BaO}$ (indicated by *), and $\mathrm{FeO}$ (identified by + ).

Figure 2. Scanning electron micrographs obtained on longitudinal polished sections of $\mathrm{BaFeO}_{\mathrm{x}}$ samples sintered at (a) 950, (b) 1100 , and (c) $1200^{\circ} \mathrm{C}$.

Figure 3. Scanning electron micrograph obtained on a representative longitudinal polished section of samples sintered at $1100^{\circ} \mathrm{C}$, where different contrasts have been observed and associated, by EDS analysis, with the phases (indicated by numbers): 1- $\mathrm{FeO}$; 2- $\mathrm{BaFe}_{2} \mathrm{O}_{\mathrm{y}}$; and 3- $\mathrm{BaFeO}_{\mathrm{x}}$.

Figure 4. $\mathrm{BaFeO}_{\mathrm{x}}$ electrical resistivity vs. temperature as a function of sintering temperature: • 950; $\square 1100$; and $\nabla 1200^{\circ} \mathrm{C}$.

Figure 5. $\mathrm{BaFeO}_{\mathrm{x}}$ seebeck coefficient vs. temperature as a function of sintering temperature: • 950; $\square 1100$; and $\nabla 1200^{\circ} \mathrm{C}$.

Figure 6. $\mathrm{BaFeO}_{x}$ power factor vs. temperature as a function of sintering temperature: • 950; $\boldsymbol{\nabla} 1100$; and $\nabla 1200^{\circ} \mathrm{C}$. 
Figure 1

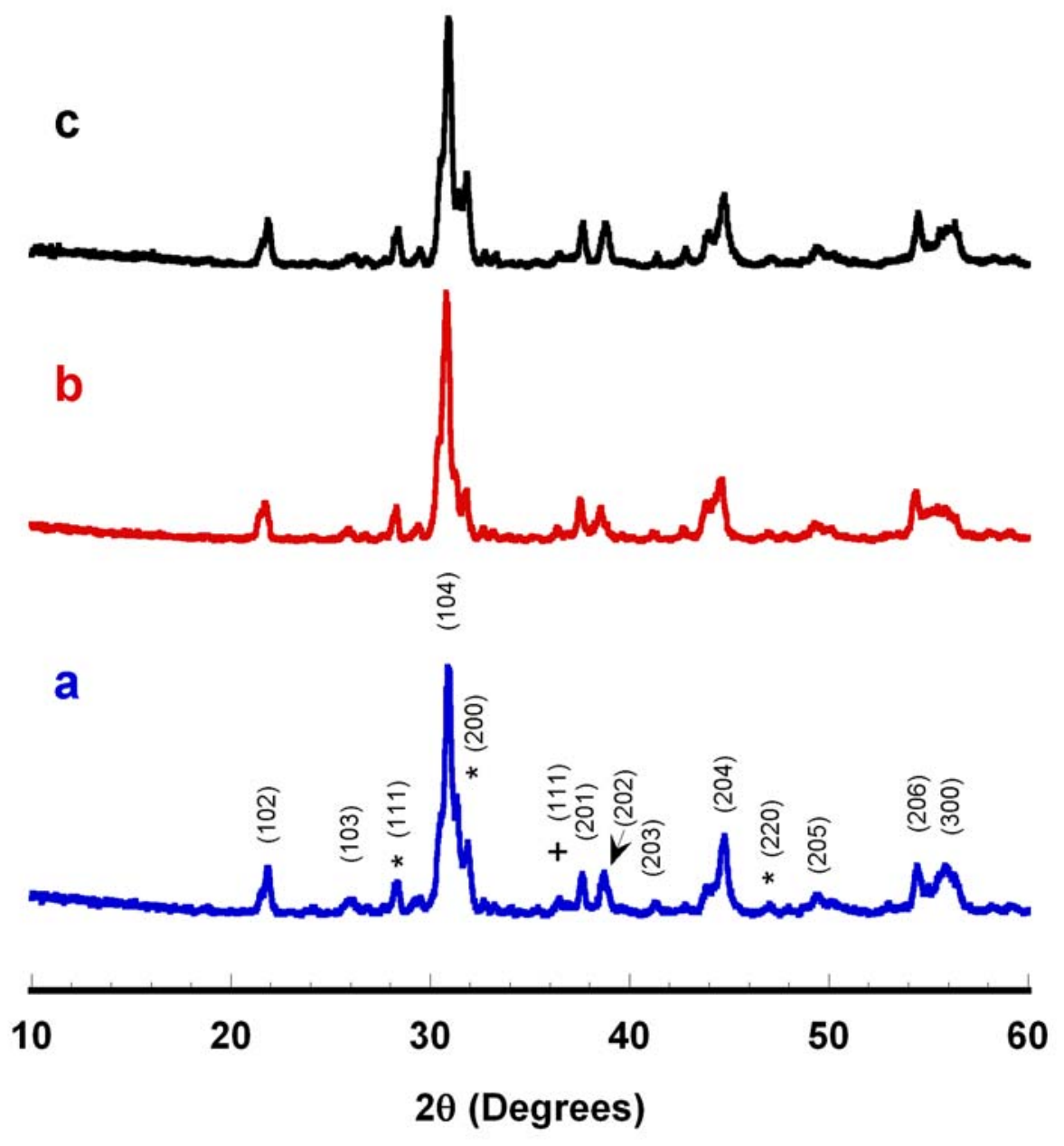


Figure 2
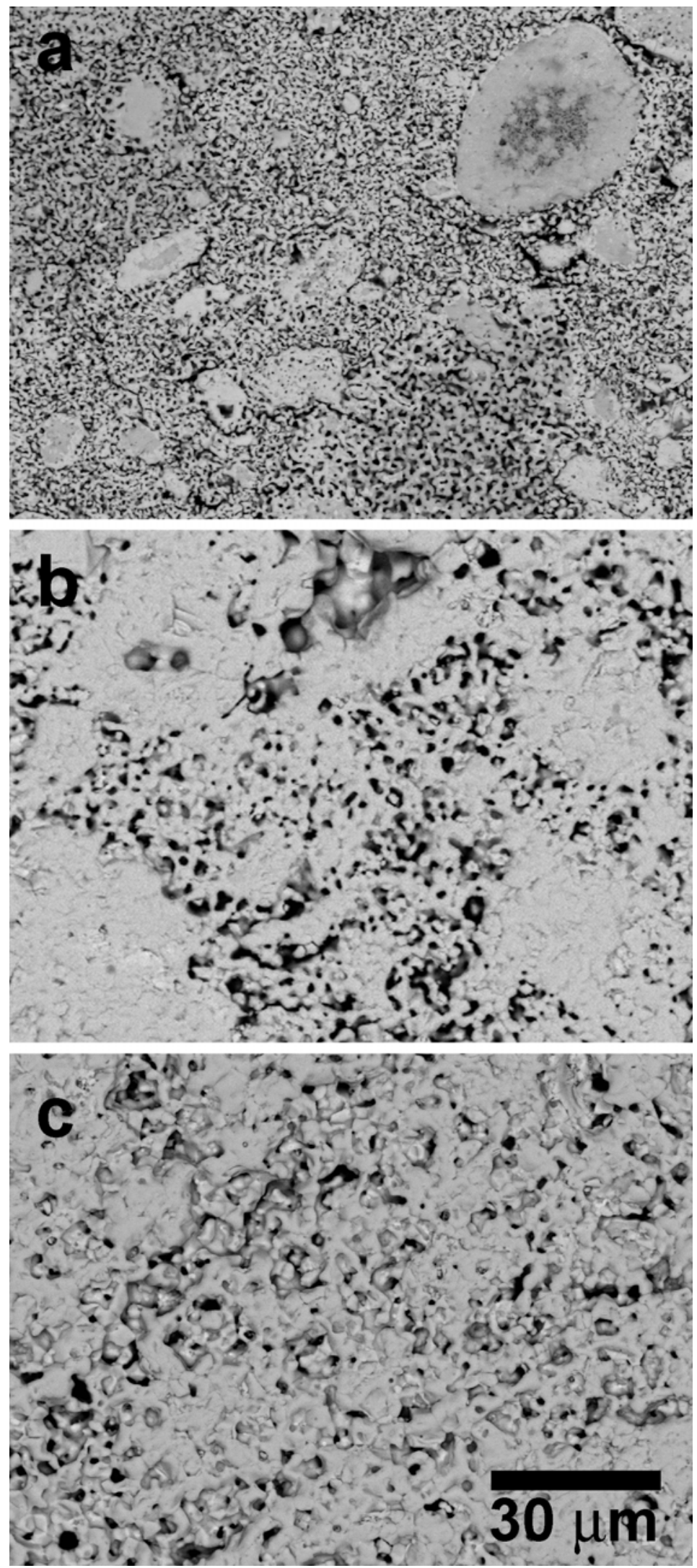
Figure 3

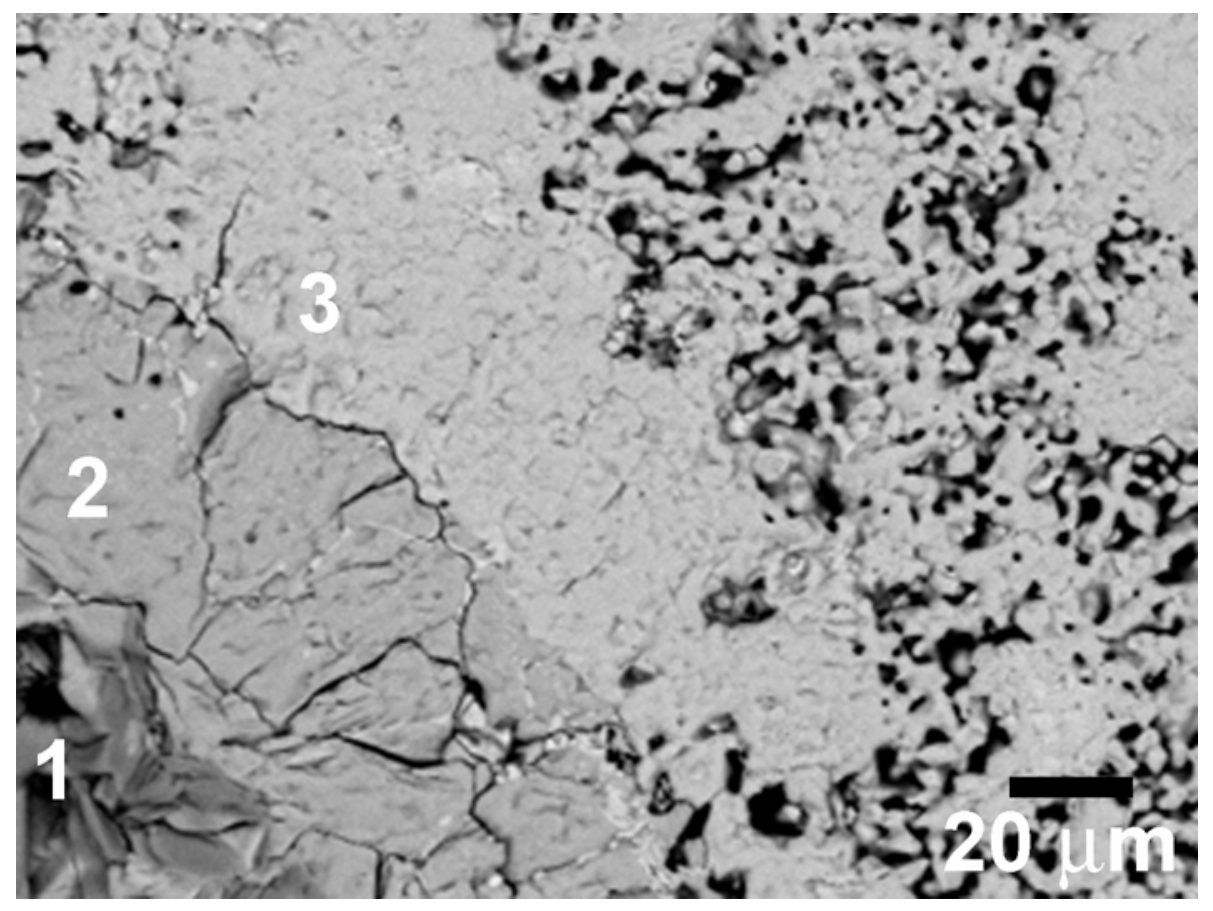


Figure 4

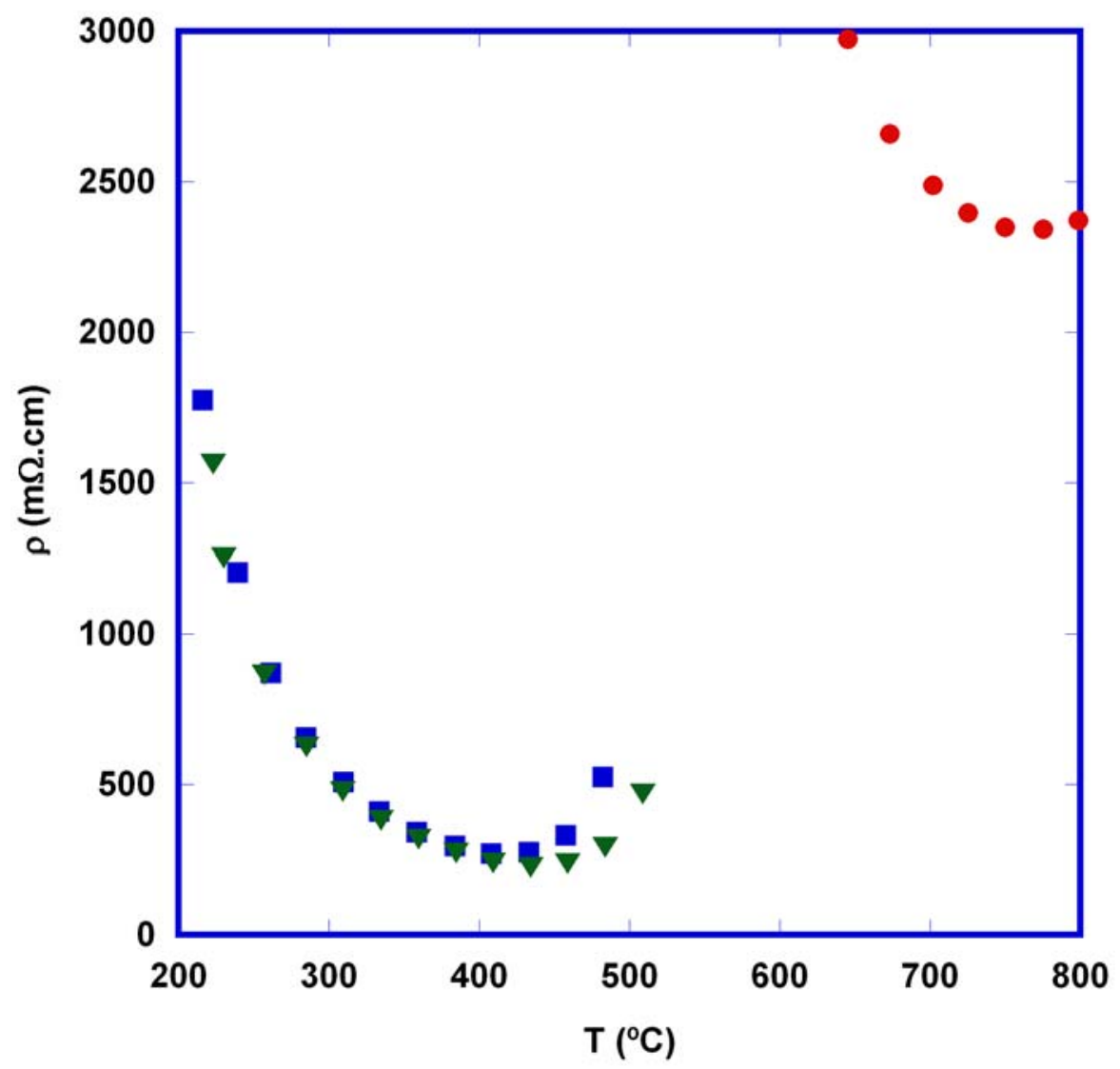


Figure 5

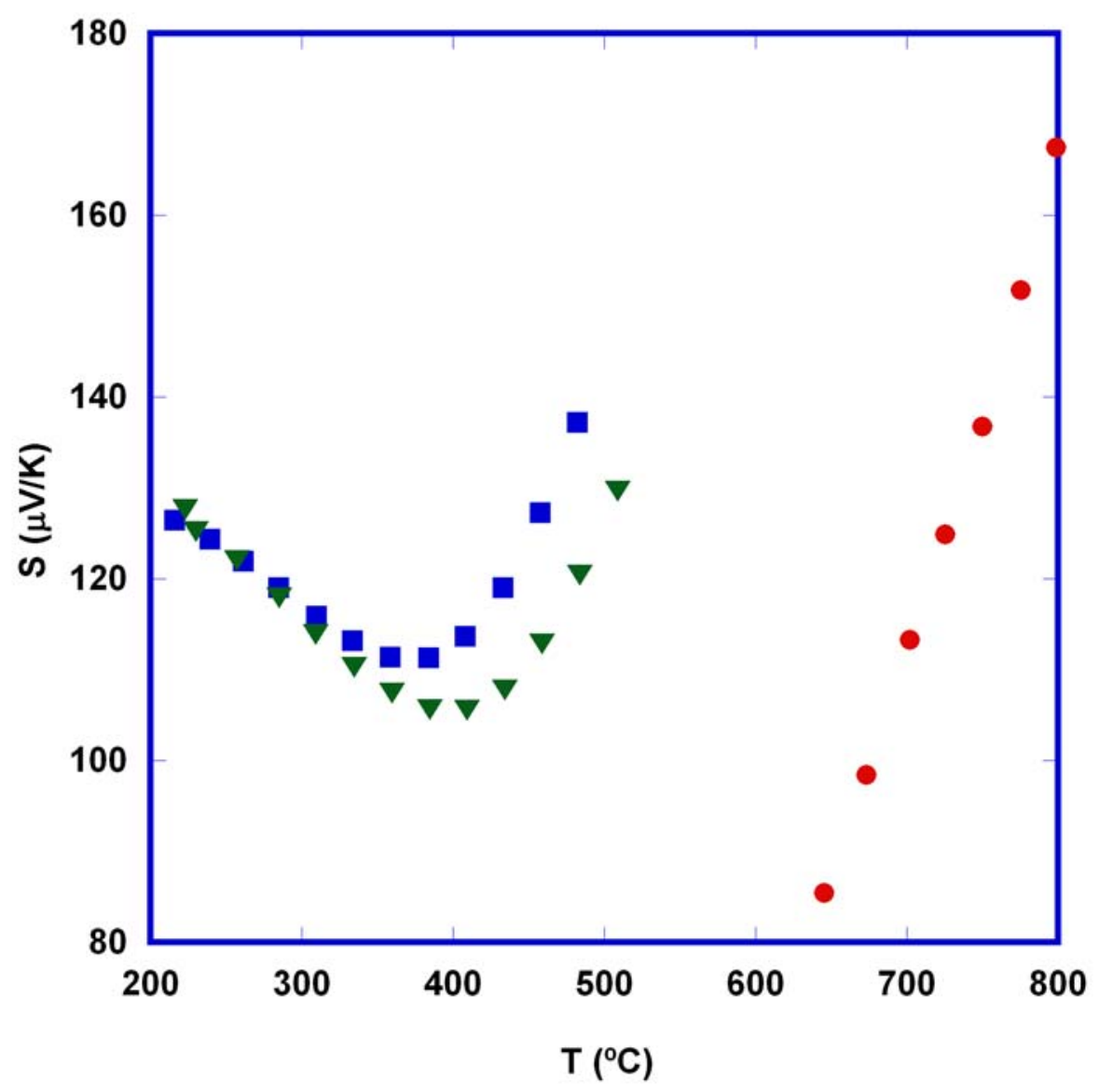


Figure 6

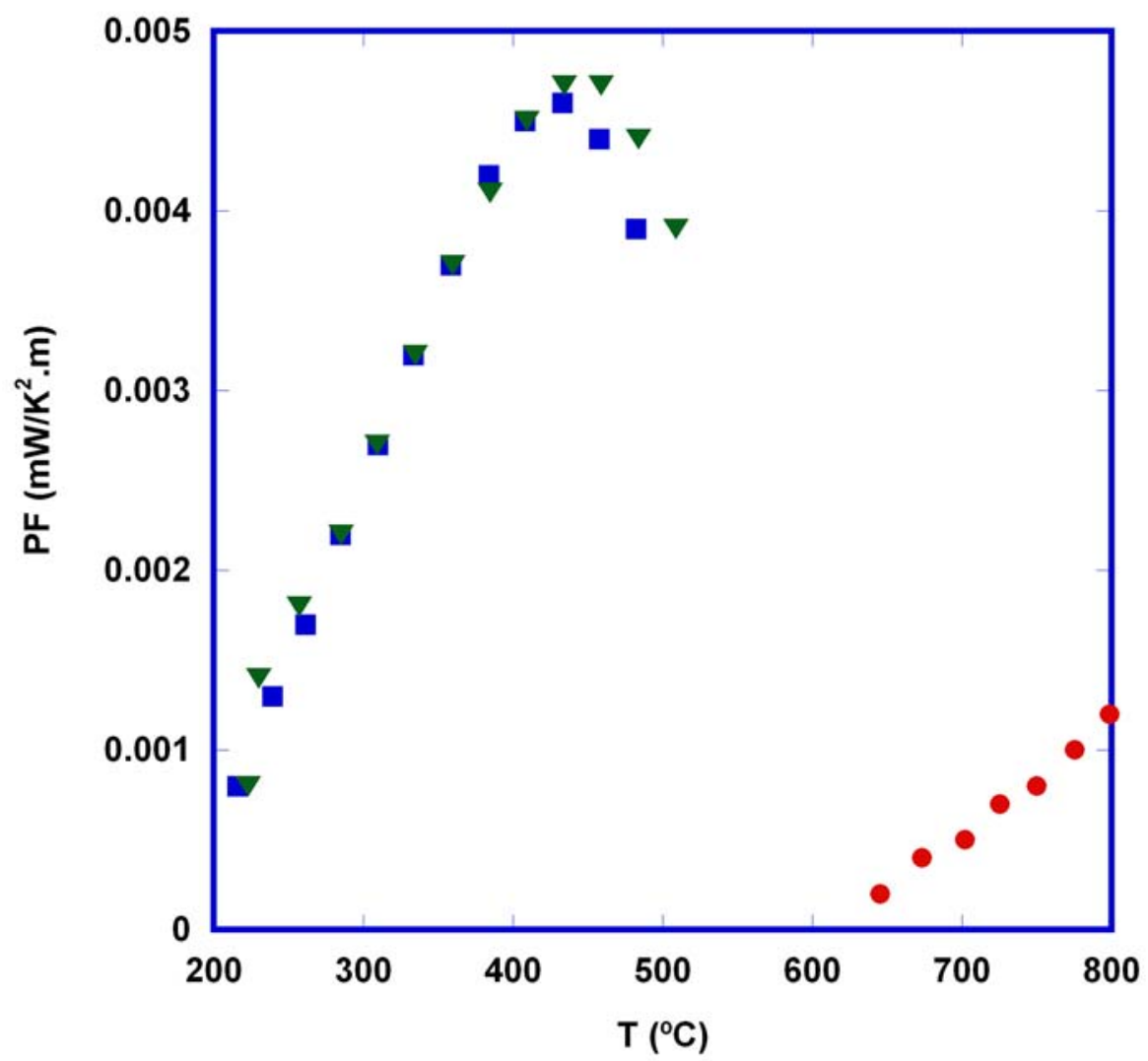

